\title{
Pituitary response to $\mathrm{LHRH}, \mathrm{LH}$ pulsatility and plasma melatonin and prolactin changes in ewe lambs treated with melatonin implants to delay puberty
}

\author{
D. J. Kennaway, J. C. Peek*, T. A. Gilmore and P. Royles \\ Department of Obstetrics and Gynaecology, University of Adelaide, Adelaide, South Australia 5000, \\ Australia
}

\begin{abstract}
Summary. Prepubertal ewe lambs were treated with empty or filled melatonin implants. The implants were placed s.c. at birth and pituitary responsiveness to various doses of LHRH, LH/FSH pulsatility and prolactin and melatonin secretion were examined at $10,19,28,36$ and 45 weeks of age. Control animals $(N=10)$ showed no consistent alteration in pituitary responsiveness to LHRH during development. Ewes treated with melatonin $(\mathrm{N}=10)$ had puberty onset delayed by 4 weeks $(P<0.03)$ but no effect of melatonin on LH or FSH response to LHRH injection was observed at any stage of development. In the control and melatonin-treated ewe lambs the responses to LHRH injection were lower during darkness than during the day at all stages of development. No consistent differences in LH or FSH pulsatility were observed between treatment groups or during development. Prolactin concentrations, however, failed to decrease at the time of puberty (autumn) in the melatonin-treated group. Melatonin-treated ewe lambs maintained normal rhythmic melatonin production which was superimposed on a higher basal concentration and showed the same increase in melatonin output with age as the control ewes. These results indicate that the delayed puberty caused by melatonin implants is not due to decreased pituitary responsiveness to LHRH or to dramatic changes in basal LH or FSH secretion.
\end{abstract}

\section{Introduction}

The onset of puberty in ewe lambs is determined by seasonal, environmental influences. It is now widely believed that environmental photoperiodic changes are as important in sexual maturation as they are in programming the breeding season of mature animals. It has been shown for example that ewe lambs born in autumn do not exhibit overt signs of sexual maturity until the following autumn, coincident with sexual maturity of younger, lighter spring born lambs (Foster, 1981). It would appear that the increasing daylength between winter and summer is responsible for preventing premature maturity. Nutritional status also obviously plays an important part in puberty, affecting fundamental aspects of gonadotrophin output, such as pulsatility and steroid feedback (Foster \& Olster, 1985). As for many other species there appears to be a critical weight requirement for sheep; animals below the critical weight have delayed puberty.

Attempts have been made to define the critical light requirements for normal puberty onset. If ewe lambs are maintained from birth in constant long or constant short daylength, puberty is delayed (Yellon \& Foster, 1985). Furthermore, short daylength is only stimulatory if ewe lambs have been exposed to long daylength between 10 and 20 weeks of age (Yellon \& Foster, 1985).

*Present address: Postgraduate School of Obstetrics and Gynaecology, National Women's Hospital, Claude Road, Auckland 3, New Zealand. 
There is, therefore, some form of programming occurring many weeks before the actual onset of reproductive cyclicity. Photoperiodic control of puberty may involve the pineal hormone melatonin, since constant melatonin administration after 3 weeks of age delays puberty in ewe lambs (Kennaway \& Gilmore, 1984). The delayed puberty observed in that study is in contrast to the effects of melatonin treatment after the critical period in prepubertal lambs and adult ewes whereby constant melatonin treatment promotes ovarian activity (Nowak \& Rodway, 1985). Early melatonin treatment of lambs is thought to interfere with the development of the circadian rhythm of sensitivity to melatonin (Kennaway \& Gilmore, 1984). This was confirmed when ewe lambs were pinealectomized at 10 weeks of age (Kennaway, Dunstan \& Gilmore, 1985). Pinealectomized lambs also had delayed puberty but more importantly these ewes have continued to have breeding seasons considerably out of phase with the normal breeding season.

In this communication we report the effects of stage of development on pituitary LHRH sensitivity in the ewe lamb. Of particular interest was the possibility that there may be an altered response to LHRH during development and that sensitivity to LHRH may be altered during the night. If this were the case, it might aid understanding of the role of photoperiod in the control of puberty. We also studied LH and FSH pulse frequency in daylight and darkness, the 24-h pattern of prolactin secretion and changes in melatonin secretion during development. As a test of the hypothesis that the melatonin-induced delayed puberty previously reported by us (Kennaway \& Gilmore, 1984) was caused by alterations in LHRH responsiveness, we also studied ewe lambs implanted with melatonin sachets from birth.

\section{Materials and Methods}

The experiment was conducted at the Mortlock Experiment Station, Mintaro, South Australia, between July 1983 and May 1984. Border Leicester $\times$ Merino ewes were mated with Dorset rams and provided a July lambing. Ewe lambs born between 4 and 26 July 1983 were used. Ten lambs were implanted subcutaneously with Silastic envelopes containing crystalline melatonin, at birth and at 13 weeks of age (Kennaway \& Gilmore, 1984). The remaining 10 ewe lambs were implanted with empty envelopes. At 10, 19, 28, 36 and 45 weeks of age all 20 lambs were studied intensively over a $21-\mathrm{h}$ period in an open shed. The duration of darkness at these times was $11 \cdot 6,9 \cdot 7,10 \cdot 2,11 \cdot 9$ and $13.9 \mathrm{~h}$ respectively. Four treatment groups were established;

Group CC $(\mathrm{N}=5)$ had empty implants and had only intensive blood sampling performed

Group $\mathrm{CL}_{\mathrm{L}}(\mathrm{N}=5)$ had empty implants and were tested with LHRH

Group MC $(\mathbf{N}=5)$ had melatonin implants and intensive blood sampling and

Group ML $(N=5)$ had melatonin implants and were tested with LHRH.

The intensive blood sampling periods used in Groups $\mathrm{CC}$ and $\mathrm{MC}$ were designed to cover a 4-h period in daylight and a 7-h period around sunset. Sampling frequency was every $15 \mathrm{~min}$ in daylight and every $30 \mathrm{~min}$ in the evening. At $6 \mathrm{~h}$ after sunset sampling frequency changed to hourly until dawn (Fig. 1).

Blood sampling during darkness was facilitated by dim red safe lights and small red 'pen' lights. The regimen for Groups $C_{L}$ and $M_{L}$ is also shown in Fig. 1. After several pretreatment samples ewe lambs were injected intravenously with increasing doses of LHRH (Relefact, Hoechst (Australia Ltd, St Kilda, Victoria, Australia) on the hour with 15-min samples obtained between injections. The three doses used were $0 \cdot 2,2$ and $20 \mathrm{ng} / \mathrm{kg}$ body weight. These injections began at 12:00 h on each occasion. For the night injections a sample was obtained $2 \mathrm{~h}$ after sunset $(4 \cdot 75-7 \cdot 75 \mathrm{~h}$ after the last daylight injection) and the same doses of LHRH were injected over the next $3 \mathrm{~h}$ with blood sampling between injections every $20 \mathrm{~min}$.

All lambs were run at pasture between intensive bleeds and brought in weekly for single blood samples for the first 52 weeks of life. They were weaned at 14 weeks of age and run with vasectomized 

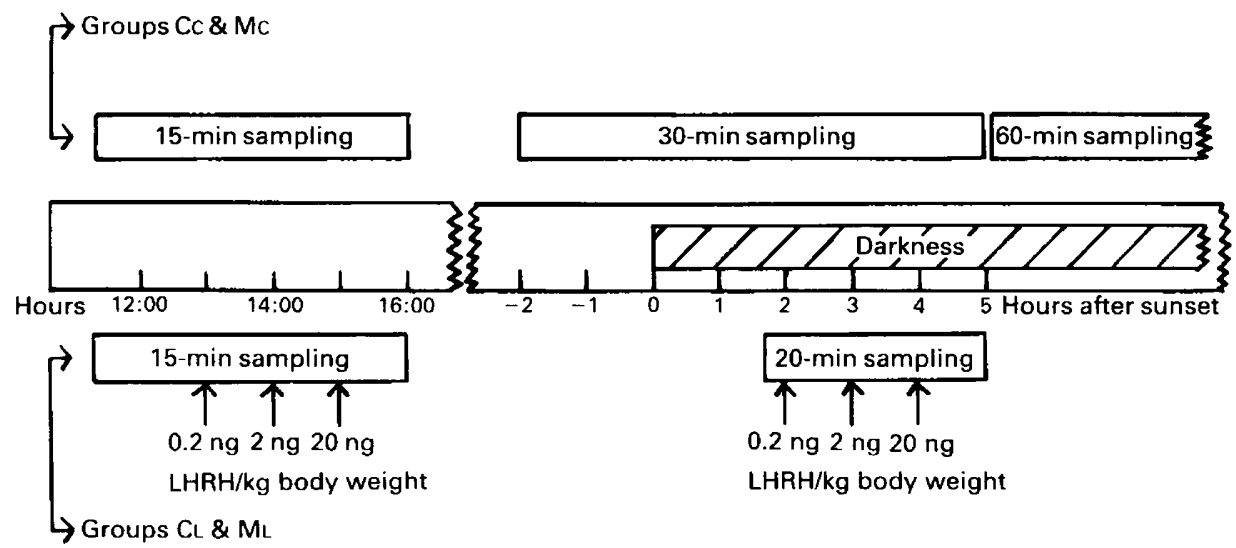

Fig. 1. Experimental design incorporating the periods of sample collecting for control and melatonin-implanted ewe lambs (Groups $\mathrm{CC} \& \mathrm{MC}$ ) and the injection and sampling regimen for the LHRH-treated lambs (Groups CL \& ML). The same protocol was used at 10, 19, 28, 36 and 45 weeks of age.

rams continuously from that time. Lambs were checked at weekly intervals for crayon marks as an indication of oestrus.

Progesterone was assayed by RIA (Janson, Amato, Weiss, Ralph \& Seamark, 1978). Sensitivity of the assay was in the range $0.5-0.8 \mathrm{nmol} / 1$ and intra- and inter-assay coefficients of variation were $<12 \%$ at $7 \mathrm{nmol} / 1$.

Melatonin was assayed by a modification of our RIA (Kennaway, Gilmore \& Seamark, 1982a) without prior chromatography (Earl, D’Occhio, Kennaway \& Seamark, 1985). Sensitivity of the assay was $60-86 \mathrm{pmol} / \mathrm{l}$ and intra- and inter-assay coefficients of variation at $310 \mathrm{pmol} / 1$ were 15 and $24 \%$ respectively.

Luteinizing hormone (LH) was assayed by RIA (Kennaway \& Gilmore, 1985). The sensitivity using NIH-LH-S19 as standard was $0 \cdot 3-0 \cdot 5 \mu \mathrm{g} / 1$ with intra- and inter-assay coefficients of variation of $10 \%$ and $14 \%$ at $2 \cdot 1 \mu \mathrm{g} / \mathrm{l}$ and $10 \%$ and $20 \%$ at $9 \cdot 6 \mu \mathrm{g} / 1$.

Follicle-stimulating hormone (FSH) was assayed by the RIA method of Cheng, Simaraks \& Palmer (1981). Sensitivity was $<2 \mu \mathrm{g} / 1$ using NIH-FSH-S15 as standard. Intra- and inter-assay coefficients of variation were $<15 \%$ over the range $10-50 \mu \mathrm{g} / \mathrm{l}$.

Prolactin was assayed by RIA (Kennaway, Obst, Dunstan \& Friesen, 1981). Sensitivity of the assay was $<3 \mu \mathrm{g} / 1$ using NIH-PRL-S1 3 as standard. Intra- and inter-assay coefficients of variation were $<10 \%$ through the range $10-300 \mu \mathrm{g} / \mathrm{l}$.

Statistical analyses of the responses to LHRH injection, and melatonin and prolactin concentrations during development consisted of one- and two-way analyses of variance. Differences between specific groups were tested by the Neuman-Keuls test. Puberty was defined as occurring the week that progesterone levels were in excess of $1.5 \mathrm{nmol} / 1$. The effect of melatonin treatment on puberty onset was tested using the Mann-Whitney $U$ test. LH pulse frequency was determined by the objective method of Clifton \& Steiner (1983).

\section{Results}

\section{Melatonin concentrations and onset of puberty}

Treatment of ewe lambs with melatonin implants at birth resulted in relatively constant daylight values of melatonin throughout the study. The mean ' \pm s.e.m.) concentration (pmol/l) was 
$204 \pm 21$ at 10 weeks of age, $386 \pm 41$ at 19 weeks, $320 \pm 34$ at 28 weeks, $284 \pm 32$ at 36 weeks, and $228 \pm 26$ at 45 weeks. Blood concentrations of melatonin in ewe lambs with empty implants were always $<80 \mathrm{pmol} / \mathrm{l}$.

Puberty was significantly delayed $(P=0.01)$ by treatment with melatonin implants; the median age of onset was 39 weeks (97\% confidence interval (CI) 36-44) compared with a median age of onset of 44.5 weeks $(97 \%$ CI 41-49) in the melatonin-treated ewes. Puberty onset occurred 28 days later in the year in melatonin-treated ewes (Day $106 \pm \cdot 7 \cdot 9 v s$ Day $134 \pm 8 \cdot 8, P=0 \cdot 03$ ). Melatonin treatment did not have any effect on body weight during the study.

\section{$L H$ response to $L H R H$ injections}

Injection of $0 \cdot 2,2$ or $20 \mathrm{ng} \mathrm{LHRH} / \mathrm{kg}$ into ewe lambs of Groups $\mathrm{CL}_{\mathrm{L}}$ and $\mathrm{ML}$ resulted in a dose-dependent release of $\mathrm{LH}$ at all stages of development. Figure 2 shows the mean LH values
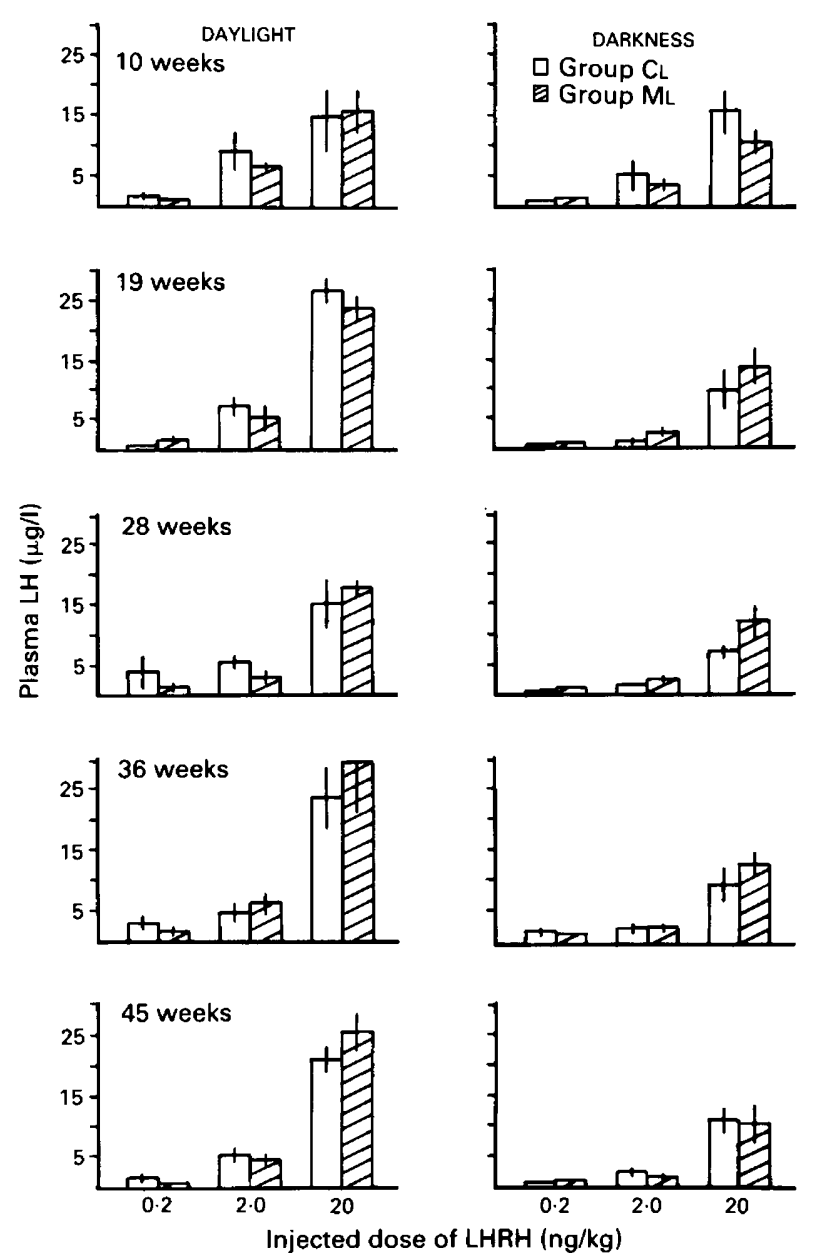

Fig. 2. Peak LH responses to graded doses of LHRH in control and melatonin-implanted ewe lambs during development. Values are mean \pm s.e.m. The left-hand panels show results from LHRH challenges during daylight while the right-hand panels are from the same animals treated $2 \mathrm{~h}$ after darkness. 
$15 \mathrm{~min}$ (day) and $20 \mathrm{~min}$ (night) after injection of the 3 doses of LHRH. At 10 weeks of age some results had to be excluded because endogenous pulses of LH in the period before injection clearly affected the LHRH response. The LH responses during the day were remarkably similar throughout the study and no significant changes in response were evident at any dose of LHRH in Group $\mathrm{CL}_{L}$ or ML.

When LHRH was injected into ewe lambs $2 \mathrm{~h}$ after sunset there was again a dose-dependent response of $\mathrm{LH}$ secretion; however, the quantitative release of $\mathrm{LH}$ was significantly less than that which occurred during the daylight $(P<0.01)$. This difference could not be attributed solely to the different sampling frequency since the difference between day and night was evident even if correction was made for the 20 -min versus 15 -min sampling in darkness and daylight. Also, when the area under the response curves was calculated, a similar conclusion was reached. As during daylight, there was no significant change in the nocturnal LH response to LHRH during development.
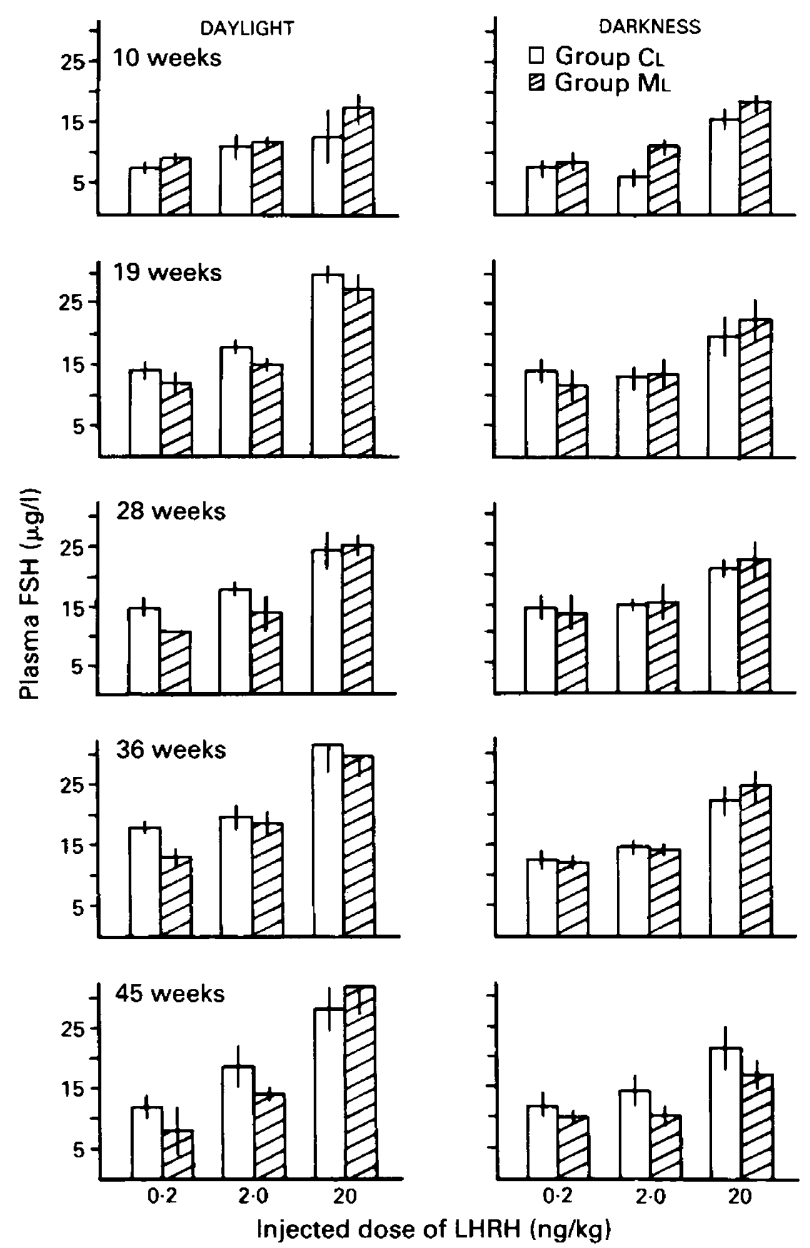

Fig. 3. Peak FSH responses to graded doses of $\mathrm{LHRH}$ in control (Group $\mathrm{CL}$ ) and melatoninimplanted (Group ML) ewe lambs during development. Values are mean \pm s.e.m. The left-hand panels show results from LHRH challenges during daylight while the right-hand panels are from the same animals treated $2 \mathrm{~h}$ after darkness. 


\section{FSH response to LHRH injections}

Injection of LHRH caused release of FSH into blood of all animals during daylight and darkness (Fig. 3). There was, however, no change in the FSH response during development and no effect of melatonin treatment. As with $\mathrm{LH}$, there was significantly less FSH released in response to LHRH injection at night throughout development in the control and melatonin-implanted ewe lambs. The LH/FSH ratio similarly was not altered during development and was not affected by melatonin treatment (data not shown).

\section{Basal LH and FSH concentrations}

Secretion of both LH and FSH was pulsatile at all stages of development in control and melatonin-implanted lambs. Table 1 shows the number of pulses observed during the daylight and night sampling periods. There was no significant difference in the number of pulses between treatment groups or between day and night. There were, however, significantly more LH and FSH pulses at 10 and 45 weeks of age compared with the other ages studied. The amplitude of the pulses varied considerably within and between animals; peak LH values were often in excess of $10 \mu \mathrm{g} / 1$ (Table 2). Such high amplitudes were typically observed during all stages of the experiment and were not affected by melatonin treatment. When mean LH concentrations or the areas under the pulse curves were calculated there was a significant age effect with the control group (Cc) having significantly higher $\mathrm{LH}$ output at 10 and 45 weeks while the melatonin-treated group had high output at 10 weeks of age only.

Table 1. Effect of age, melatonin treatment and time of day on the number of LH pulses $/ \mathrm{h}$ (mean \pm s.e.m.)

\begin{tabular}{|c|c|c|c|c|c|c|}
\hline \multirow[b]{2}{*}{ Treatment } & \multirow{2}{*}{$\begin{array}{l}\text { Time of } \\
\text { sampling }\end{array}$} & \multicolumn{5}{|c|}{ Age in weeks } \\
\hline & & 10 & 19 & 28 & 36 & 45 \\
\hline \multirow[t]{2}{*}{ Control } & Day & $0.55 \pm 0.18$ & $0.15 \pm 0.06$ & $0 \cdot 15 \pm 0 \cdot 15$ & $0 \cdot 30 \pm 0 \cdot 15$ & $0.56 \pm 0.21$ \\
\hline & Night & $0.34 \pm 0.07$ & $0.11 \pm 0.03$ & $0.08 \pm 0.06$ & $0.20 \pm 0.10$ & $0.28 \pm 0.15$ \\
\hline \multirow{2}{*}{ Melatonin } & Day & $0.50 \pm 0.10$ & $0.15 \pm 0.06$ & $0.25 \pm 0.08$ & $0.05 \pm 0.05$ & $0.38 \pm 0.16$ \\
\hline & Night & $0.32 \pm 0.09$ & $0.08 \pm 0.03$ & $0.17 \pm 0.05$ & $0.17 \pm 0.05$ & $0.21 \pm 0.08$ \\
\hline
\end{tabular}

Summary of ANOVA: Treatment, 3 d.f., $F=2 \cdot 17, P=0.097$; Age, 4 d.f., F $=6.38, P<0.001$; Treatment $\times$ Age, 12 d.f., $\mathrm{F}=0.63, P>0.1$.

Table 2. Effect of age, melatonin treatment and time of day on the amplitude of LH pulses

\begin{tabular}{|c|c|c|c|c|c|c|}
\hline \multirow[b]{2}{*}{ Treatment } & \multirow{2}{*}{$\begin{array}{c}\text { Time of } \\
\text { sampling }\end{array}$} & \multicolumn{5}{|c|}{ Age in weeks } \\
\hline & & 10 & 19 & 28 & 36 & 45 \\
\hline \multirow[t]{2}{*}{ Control } & Day & $\begin{array}{l}8 \cdot 2 \pm 1 \cdot 3 \\
\quad(11)\end{array}$ & $6.8 \pm 0.9$ & $9 \cdot 0 \pm 1 \cdot 3$ & $2 \cdot 7 \frac{ \pm}{(5)} 0 \cdot 3$ & $8 \cdot 0 \underset{(9)}{ \pm} 1 \cdot 1$ \\
\hline & Night & $\begin{array}{c}7 \cdot 9 \pm 1.4 \\
(12)\end{array}$ & $9 \cdot 2 \underset{(4)}{ \pm} 3 \cdot 3$ & $16.0 \pm 4.9$ & $\frac{9 \cdot 3 \pm 1 \cdot 6}{(7)}$ & $6.9 \pm 0.8$ \\
\hline \multirow[t]{2}{*}{ Melatonin } & Day & $11 \cdot 8 \underset{(8)}{ \pm} 1.9$ & $4 \cdot 1 \pm 0.5$ & $5 \cdot 4 \pm 0.8$ & $\begin{array}{l}18 \cdot 9 \\
\text { (1) }\end{array}$ & $5 \cdot 1 \underset{(6)}{ \pm} 1 \cdot 3$ \\
\hline & Night & $9 \cdot 8 \pm 2 \cdot 0$ & $6 \cdot 4 \underset{(3)}{ \pm} 1 \cdot 8$ & $4.5 \pm 0.8$ & $\underset{(6)}{6 \cdot 3 \pm 1 \cdot 2}$ & $6.0 \pm 1.6$ \\
\hline
\end{tabular}

The results are expressed as the mean \pm s.e.m. of the total number of pulses in each group.

Summary of ANOVA: Treatment, 3 d.f., $F=2.468, P=0.065 ;$ Age, 4 d.f., $F=1.61, P=0.176 ;$ Treatment $\times$ Age, 12 d.f., $\mathrm{F}=3.47, P<0.001$. 


\section{Prolactin}

Prolactin concentrations were assayed in the weekly blood samples during the first 50 weeks of life. As might be expected from animals kept in field conditions and mustered weekly for blood sampling, the prolactin values were quite variable within and between animals. Median prolactin concentrations were therefore calculated for each sheep over 10-week intervals and then group means were calculated. The control ewe lambs had low prolactin during the first 10 weeks of life and the highest levels were reached between 21 and 30 weeks and then declined. The period of elevated prolactin coincided with the long days around the time of the summer solstice. In contrast, the melatonin-treated animals had low prolactin values early in development, but concentrations continued to increase throughout the period of study such that during the period of $40-50$ weeks of age the melatonin-treated group had significantly higher prolactin values than did the control group (Fig. 4).

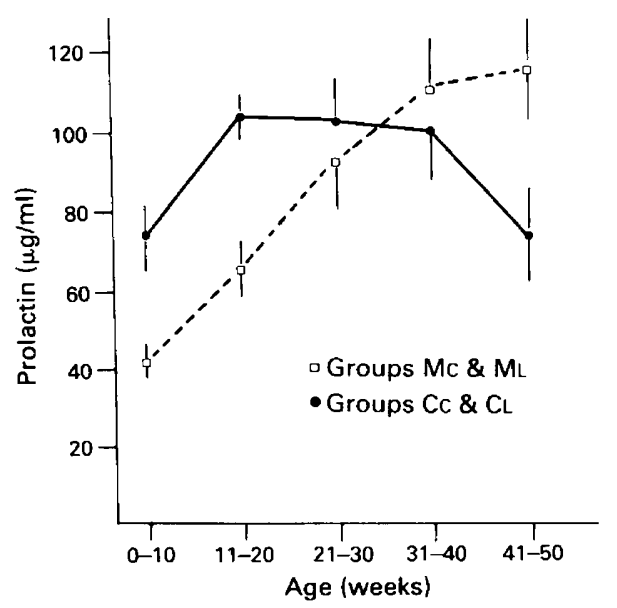

Fig. 4. Prolactin concentrations in ewe lambs during development. Median prolactin values over 10-week periods were obtained for individual lambs and are presented as the mean \pm s.e.m. of 10 animals.

Plasma prolactin concentrations during the intensive bleeding periods were relatively stable within animals and no consistent prolactin release coincident with LH/FSH pulses was evident. The pattern of prolactin secretion during darkness varied markedly during development (Fig. 5). A pronounced surge of prolactin was evident around dusk at 10 and 19 weeks when the daylength was increasing, but this surge had diminished in magnitude by 28 weeks and was absent during later stages of development. This developmental change was evident in the control and melatonin groups despite the higher basal prolactin values in melatonin-treated ewes compared with the control ewes at Week 45.

\section{Melatonin circadian rhythm}

Because we wished to keep the total volume of blood taken from the ewe lambs at a minimum (especially at 10 weeks) and because we wished to minimize the number of melatonin analyses, we did not obtain complete hour-by-hour profiles of melatonin secretion. Instead, we took $200 \mu \mathrm{l}$ aliquants of plasma from each sample collected from $1 \mathrm{~h}$ after sunset until $1 \mathrm{~h}$ before sunrise for each individual animal and pooled them. The melatonin value of these individual pools thus represents 


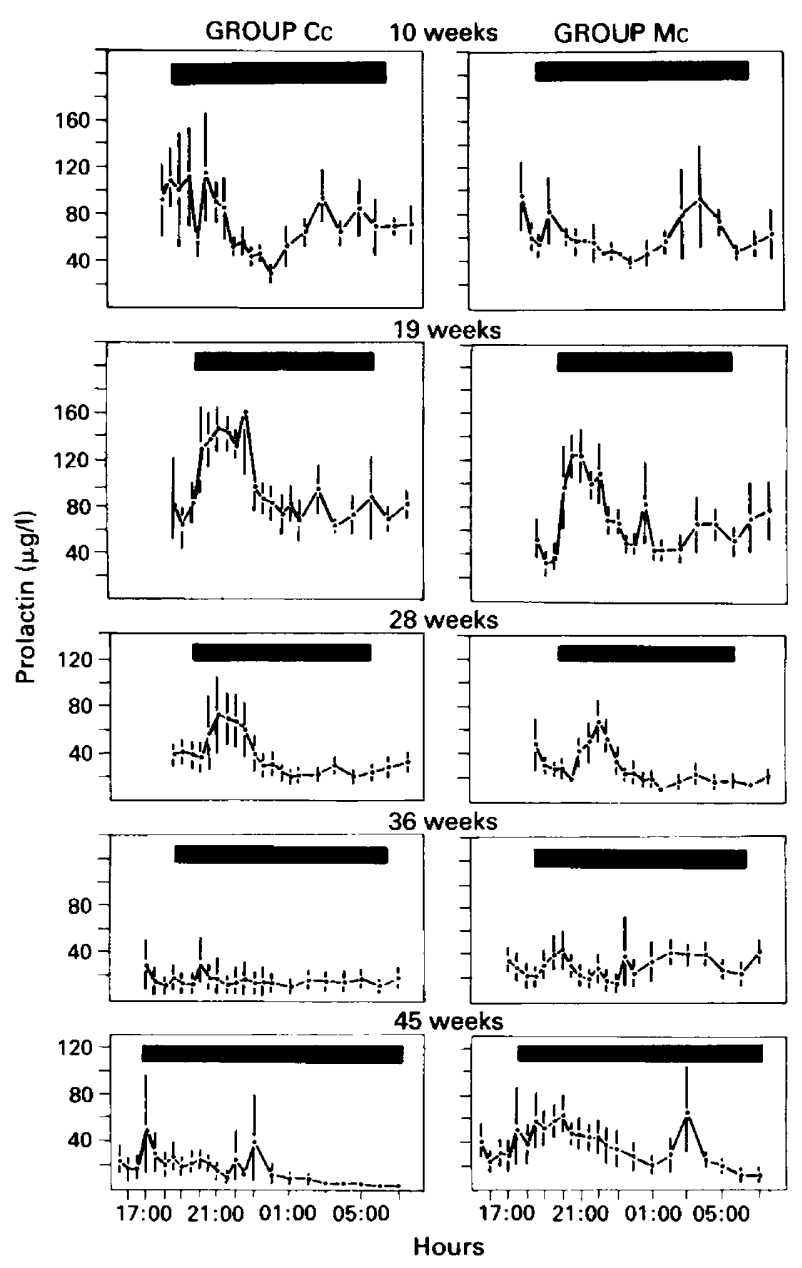

Fig. 5. Prolactin concentrations during late afternoon and darkness in ewe lambs in Group CC and $\mathrm{Mc}$ during development. Values are mean \pm s.e.m. for 5 animals. The horizontal black bars indicate the duration of the dark period.

the 'amplitude' of the melatonin rhythm for each animal. In addition, we assayed the 4 samples obtained around the time of sunset and 4 samples around dawn at each stage of development in Groups $\mathrm{CC}$ and MC. Figure 6 shows that the night-time mean melatonin concentrations in control ewe lambs were lowest at 10 weeks and highest at 45 weeks. At 28 weeks, the melatonin values were significantly lower $(P<0 \cdot 01)$ than those at 19 or 36 weeks. The Group MC ewe lambs had night-time melatonin values $200-300 \mathrm{pmol} / 1$ higher than those of Group Cc ewes at each stage of development. Melatonin-implanted animals had a similar pattern of change in night-time levels, but the 19-28-week decrease was not significant whereas the 28-36-week increase was significant $(P<0.05)$.

When the sunset and sunrise periods were investigated, the timing of the rise in melatonin blood levels were similar for ewe lambs in Groups $\mathrm{CC}$ and $\mathrm{MC}$ at sunset and the fall at dawn throughout development (data not shown). The delayed puberty observed in Group Mc and ML ewes could not therefore be attributed to the implants affecting the phase of the melatonin rhythm. 


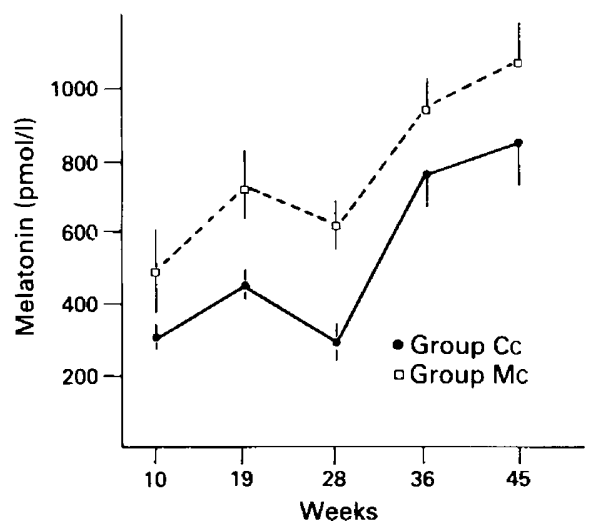

Fig. 6. Night-time melatonin concentrations in ewe lambs during development. Aliquants of plasma obtained during darkness were pooled and are presented as mean \pm s.e.m. for 5 animals in each group.

\section{Discussion}

These results confirm our previous finding that treatment of lambs at 3 weeks of age or earlier with melatonin implants will delay puberty in ewe lambs (Kennaway \& Gilmore, 1984). Puberty occurred at the same time of the year as in the previous study but because the lambs were born up to 4 weeks later the median age of puberty was younger. We have suggested that the delayed puberty may be due to a decreased pituitary response to LHRH at some stage during development (Kennaway \& Gilmore, 1984). In neonatal rats melatonin has been shown to inhibit the pituitary response to LHRH in vitro and in vivo (Martin, Engel \& Klein, 1977). This inhibition was absent in adult rats. There is also some evidence that female sheep have a changing response to LHRH during early development (Tyrell, Starr, Restall \& Donnelly, 1980).

In the present study we used graded doses of LHRH to address the question of pituitary responsiveness to LHRH. Doses of LHRH of $0 \cdot 2,2$ and $20 \mathrm{ng} / \mathrm{kg}$ body weight resulted in a dosedependent release of $\mathrm{LH}$ into peripheral blood at all stages of development. The LH values achieved were similar to those observed during normal pulsatile discharges. In direct contrast to the results of Tyrrell et al. (1980) there was no alteration in peak LH responses between 10 and 45 weeks of age. A possible explanation for this discrepancy is that the doses of LHRH used by Tyrrell et al. (1980) resulted in 'surge-like' LH releases and thus the results represent changes in the total releaseable pool of $\mathrm{LH}$.

The FSH responses to the three LHRH doses did not change during the period of study. FSH was released in a dose-dependent manner with the levels achieved with the dose of $2 \mathrm{ng} \mathrm{LHRH} / \mathrm{kg}$ being similar to endogenous pulse values.

When the LHRH injections were repeated $2 \mathrm{~h}$ after darkness at 10, 19, 28, 36 and 45 weeks of age there was again a dose-dependent release of LH and FSH into peripheral blood. The peak responses to the 3 injections were not affected by the age of the ewe lambs. The night-time peak responses were, however, significantly lower than the daytime responses at the 2 and $20 \mathrm{ng} / \mathrm{kg}$ doses at all stages of development. Sampling at night was at 20-min intervals rather than 15 min due to the extra difficulties in operating under very low intensity lighting. The significantly lower response at night was still preserved if corrections were made to account for the different sampling times. Lower LH release at night in the current experiment is unlikely to be due to down regulation of receptors normally seen after maximal pituitary LH release, since few of the LH responses to LHRH exceeded normal episodic LH levels (see below). Furthermore, McLeod, Haresign \& Lamming (1982) found that pituitary responsiveness did not decrease until at least the fourth 2-h injection of 
$20 \mathrm{ng} \mathrm{LHRH} / \mathrm{kg}$, i.e. the maximum dose we used. At the time of this lower sensitivity to exogenous LHRH the amplitudes of the LH pulses were similar to the daytime discharges. If the pituitary is indeed less sensitive to LHRH then the hypothalamic release of LHRH would need to be increased to compensate. Clearly, this is an area worthy of further investigation. The failure of melatonin treatment to alter LHRH sensitivity in ewe lambs confirms a previous study by Rodway \& Swift (1983) who found that prior injection of melatonin failed to alter the LH response to $1000 \mathrm{ng}$ LHRH/kg during development. Symons \& Arendt (1982) similarly tested the effect of acute melatonin administration on the response of $100 \mu \mathrm{g}$ LHRH in adults and found no differences. Symons \& Arendt (1982) did not observe any difference between day and night LHRH challenge with this high dose of LHRH.

The nature of these experiments with LHRH injection allowed an assessment of the time course of LH secretion after LHRH injections. Previous studies with high doses of LHRH in ewe lambs (Rodway \& Swift, 1983) and ram lambs (Galloway \& Pelletier, 1974) indicated that the pituitary response to LHRH was progressively slower with increasing age. In our studies the half-life of released LH was of the order of 35-45 min and did not vary significantly with age, melatonin teatment, dose of LHRH or time of day. The calculated half-life of FSH $(\sim 80 \mathrm{~min})$ similarly was constant throughout the study.

The inconsistent nature of the episodic $\mathrm{LH}$ secretion during development of normal ewe lambs is in agreement with a previous extensive study by Foster, Lemons, Jaffe \& Niswender (1975). It was not surprising, therefore, that melatonin treatment similarly had no consistent effect upon LH pulse frequency or amplitude. Foster, Yellon \& Olster (1985) suggested that the LH pulse frequency subtly increases before puberty in response to changes in oestradiol sensitivity. The slightly higher pulse frequencies we observed at 45 weeks may be a reflection of this. The higher pulse frequency at 10 weeks is more difficult to explain apart from the stress of sampling such young animals. In view of the photoperiodic control of puberty in ewes and the observation of a nocturnal rise in LH in prepubertal boys (Boyar et al., 1972), we investigated LH secretion during the dark period throughout development. The lack of treatment effects or development changes in the pattern of LH release at night would appear to preclude circadian rhythms of LH secretion being a determinant of puberty in ewe lambs. As discussed above, however, we did observe marked sensitivity changes to LHRH at night which may point to alterations in hypothalamic release of and pituitary sensitivity to endogenous LHRH.

When the LH and FSH results for the daylight sampling periods were averaged for each animal, levels tended to be high at 10 weeks (due to the higher pulse frequency), low between 19 and 36 weeks and high at 45 weeks in the control group. Two-way analysis of variance did not indicate a significant treatment age interaction, but ewe lambs in Group Mc secreted only half as much LH during the Week-45 sampling period as did those in Group Cc. This was due not only to a change in pulse frequency, but also to increased basal LH secretion in the control group. The apparent high FSH levels observed by Foster et al. (1975) between 10 and 30 weeks were not observed in this study. The actual FSH concentrations we measured were about 10 -fold lower than those previously assayed by Foster $e$ t al. (1975), due probably to differences in the purity of the FSH standards and a more specific FSH antibody in the present study.

The developmental pattern of prolactin concentrations in Groups $\mathrm{CC}$ and $\mathrm{Mc}$ was identical to the pattern we observed previously in this breed of sheep (Kennaway \& Gilmore, 1984). Melatonintreated lambs showed no decrease in prolactin concentrations coincident with shortening daylength in contrast to the control lambs. In fact, the prolactin values continued to increase throughout the period of study. We have no explanation for why melatonin should initially suppress prolactin and then permit inappropriately high secretion. We have observed a similar sustained rise in pinealectomized ewe lambs (D. J. Kennaway, unpublished results). This developmental pattern was also evident when the circadian patterns of prolactin concentrations were assessed; melatonin-treated lambs had elevated prolactin at Weeks 36 and 45 . Both groups, however, had surges of prolactin around dusk when the photoperiod was increasing; for example, in Week 19, whereas the surge was 
essentially absent during a decreasing photoperiod of about the same duration ( 28 weeks). This is further confirmation that the long daylength prolactin surge is not mediated by pineal influences. We have previously reported the occurrence of the dusk surge in prolactin in pinealectomized adult ewes in spring and its disappearance after an abrupt shift to short daylength (Kennaway, Dunstan, Gilmore \& Seamark, 1982). Rodway, Brinklow, Crump, Oliver \& Owen (1983) reported that a 'short day' melatonin infusion into ewes maintained in long daylength abolished the dusk surge of prolactin. In an unpublished experiment (P. F. Shaw \& D. J. Kennaway) we infused melatonin at the rate used by Rodway et al. (1983) and measured the steady state blood levels of melatonin by RIA. After such an infusion the melatonin levels were always in excess of $20000 \mathrm{pmol} / \mathrm{l}$, indicating (a) that the production rate calculated by Rollag, Morgan \& Niswender (1978) and used by Rodway et al. (1983) in their calculations was an overestimate and (b) that hormonal changes observed using this infusion rate represent pharmacological responses. Prolactin changes represent one of the most consistent physiological effects of melatonin treatment. While the mechanisms by which prolactin affects the reproductive axis are quite unknown, it would be unwise to discount a possible major role of prolactin in the control of puberty onset.

The pineal gland of lambs has been shown to respond to the rhythm of light and darkness by secreting melatonin from an early age (Rodway, Swift, Nowak, Smith \& Padwick, 1985; this study). The maintenance of the circadian rhythms of melatonin secretion in the animals implanted with melatonin is in agreement with our previous work in lambs (Kennaway \& Gilmore, 1984, 1985) and adults (Kennaway, Gilmore \& Seamark, 1982b). From our work and that of Rodway et al. (1985) it would appear that immature lambs maintained in natural conditions do not achieve adult values of melatonin until at least 36-45 weeks of age. The physiological significance of the statistically significant decrease in melatonin concentrations at 28 weeks is questionable because such a drop was not evident in the lambs studied by Rodway et al. (1985) and the melatonin-implanted ewe lambs exhibited a similar pattern.

In conclusion we have confirmed results from our previous study which showed that constant melatonin administration via implants delays puberty in ewe lambs. The delayed puberty could not be attributed to changes in pituitary responsiveness to LHRH, LH pulsatility or melatonin rhythmicity.

We thank Mr P. Geytenbeek, Mr P. Van Beusichem, Mr P. Attick and Mr P. Steele of the Waite Institute and Mortlock Experiment Station for the use of the facilities and their care of the animals; and Frank Carbone, Colin Earl, Paul Shaw and Helen Webb for technical assistance. This study was supported by a grant from the National Health and Medical Research Council of Australia.

\section{References}

Boyar, R., Finkelstein, J., Roffwarg, H., Kapen, S., Weitzman, E.D. \& Hellman, L. (1972) Synchronisation of augmented luteinizing hormone secretion with sleep during puberty. New Engl. J. Med. 287, 582-586.

Cheng, K.W., Simaraks, S. \& Palmer, W.M. (1981) Characterisation of a radioimmunoassay for ovine FSH utilizing an antibovine FSH serum. J. Reprod. Fert. 61, 115-121.

Clifton, D.K. \& Steiner, R.A. (1983) Cycle detection: a technique for estimating the frequency and amplitude of episodic fluctuations in blood hormone and substrate concentrations. Endocrinology 112, 1057-1064.

Earl, C.R., D'Occhio, M.J., Kennaway, D.J. \& Seamark, R.F. (1985) Serum melatonin profiles and endocrine responses of ewes exposed to a pulse of light late in the dark phase. Endocrinology 117, 226-230.
Foster, D.L. (1981) Mechanism for delay of first ovulation in lambs born in the wrong season (fall). Biol. Reprod. 25, 85-92.

Foster, D.L. \& Olster, D.H. (1985) Effect of restricted nutrition on puberty in the lamb: patterns of tonic luteinizing hormone ( $\mathrm{LH})$ secretion and competency of the LH surge system. Endocrinology 116, 375-381.

Foster, D.L., Lemons, J.A., Jaffe, R.B. \& Niswender, G.D. (1975) Sequential patterns of circulating luteinizing hormone and follicle stimulating hormone in female sheep from early postnatal life through the first estrous cycles. Endocrinology 97, 985-993.

Foster, D.L., Yellon, S.M. \& Olster, D.H. (1985) Internal and external determinants of the timing of puberty in the female. J. Reprod. Fert. 75, 327-344.

Galloway, D.G. \& Pelletier, J. (1974) Influence of age on 
the pituitary response of male lambs to synthetic LH-RH injection. Horm. Metab. Res. 6, 240-241.

Janson, P.O., Amato, F., Weiss, T.J., Ralph, M.M. \& Seamark, R.F. (1978) On the isolated perfused sheep ovary as a model for the study of ovarian function. Fert. Steril. 30, 230-236.

Kennaway, D.J. \& Gilmore, T.A. (1984) Effects of melatonin implants in ewe lambs. J. Reprod. Fert. 70, 39-45.

Kennaway, D.J. \& Gilmore, T.A. (1985) Effects of melatonin implants in ram lambs. J. Reprod. Fert. 73, 85-91.

Kennaway, D.J., Gilmore, T.A. \& Seamark, R.F. (1982a) Effect of melatonin feeding on serum prolactin and gonadotropin levels and the onset of seasonal estrous cyclicity in sheep. Endocrinology 110, 1766-1772.

Kennaway, D.J., Gilmore, T.A. \& Seamark, R.F. (1982b) Effects of melatonin implants on the circadian rhythm of plasma melatonin and prolactin in sheep. Endocrinology 110, 2186-2188.

Kennaway, D.J., Dunstan, E.A. \& Gilmore, T.A. (1985) Pinealectomy delays puberty in ewe lambs. J. Reprod. Fert. 74, 119-125.

Kennaway, D.J., Obst, J.M., Dunstan, E.A. \& Friesen, H.G. (1981) Ultradian and seasonal rhythms in plasma gonadotropins, prolactin, cortisol and testosterone in pinealectomized rams. Endocrinology 108, 639-646.

Kennaway, D.J., Dunstan, E.A., Gilmore, T.A. \& Seamark, R.F. (1982) Effects of shortened daylength and melatonin treatment on plasma prolactin and melatonin levels in pinealectomised and sham operated ewes. Anim. Reprod. Sci. 5, 287-294.

Martin, J.E., Engel, J.M. \& Klein, D.C. (1977) Inhibition of the in vitro pituitary response to luteinizing hormone-releasing hormone by melatonin, serotonin and 5 methoxytryptophol. Endocrinology 100, 675680 .
McLeod, B.J., Haresign, w. \& Lamming, G.E. (1982) The induction of ovulation and luteal function in seasonally anoestrous ewes treated with small-dose multiple injections of GnRH. J. Reprod. Fert. 65, 215-221.

Nowak, R. \& Rodway, R.G. (1985) Effect of intravaginal implants of melatonin on the onset of ovarian activity in adult and prepubertal ewes. $J$. Reprod. Fert. 74, 287-293.

Rodway, R.G. \& Swift, A.D. (1983) Melatonin and the pituitary response to GnRH in prepubertal and adult ewes. Horm. Metab. Res. 15, 349-351.

Rodway, R.G., Brinklow, B.B., Crump, A.D., Oliver, I. \& Owen, J. (1983) Suppression of the dusk peak of plasma prolactin by infusion of melatonin in sheep. Neuroendocrinol. Lett. 5, 359-364.

Rodway, R.G., Swift, A.D., Nowak, R., Smith, J.A. \& Padwick, D. (1985) Plasma concentrations of melatonin and the onset of puberty in female lambs. Anim. Reprod. Sci. 8, 241-246.

Rollag, M.D., Morgan, R.J. \& Niswender, G.D. (1978) Route of melatonin secretion in sheep. Endocrinology 102, $1-8$.

Symons, A.M. \& Arendt, J. (1982) Lack of effect of melatonin on the pituitary response to $\mathrm{LH}-\mathrm{RH}$ in the ewe. J. Reprod. Fert. 64, 103-106.

Tyrell, R.N., Starr, B.G., Restall, B.J. \& Donnelly, J.B. (1980) Repeatability of LH responses by lambs to monthly challenge with synthetic gonadotrophin releasing hormone (GnRH). Anim. Reprod. Sci. 3, $155-160$.

Yellon, S.M. \& Foster, D.L. (1985) Alternate photoperiods time puberty in the female lamb. Endocrinology 116, 2090-2097. 